\title{
The Accounting of the Transverse Slides for the Layered Composites
}

\section{Daryadar $\mathbf{M}^{*}$}

Department of Mathematics and Mechanics, Mechanics Institute, National Academy of Sciences of the Republic of Armenia, Armenia

*Corresponding author: Daryadar M, Department of Mathematics and Mechanics, Mechanics Institute, National Academy of Sciences of the Republic of Armenia, Armenia, Tel: 0037455791110; E-mail: m.daryadar@ymail.com

Received date: Oct 10, 2018; Accepted date: Nov 03, 2018; Published date: Nov 12, 2018

Copyright: @ 2018 Daryadar M. This is an open-access article distributed under the terms of the Creative Commons Attribution License, which permits unrestricted use, distribution, and reproduction in any medium, provided the original author and source are credited.

\section{Abstract}

The primary issues of an advanced mechanics, which are contemporary twisted, inflexible bodies, are the issues identified with ideal planning of structures. The significance and innovation of that issue are controlled by both hypothetical importance of the issue and their logical intrigue. As it is outstanding that the most powerless spots for the layered composites are the association between the layers where it isolates from one another amid distortion. That is the reason upon comparison of classical theory with adjusted theory with transverse slides accounting the latter is always preferred.
\end{abstract}

Keywords: Composite materials; Beam; Displacement; Rotation; Equilibrium; Contemporary deformed; Transverse slides; Cylindrical bending; Stability

\section{Introduction}

It is the simplest and admitted model of the transverse slides [1]. (Figure 1)

$$
u_{x}=u+z \varphi ; u_{y}=v+z \psi ; u_{z}=w
$$

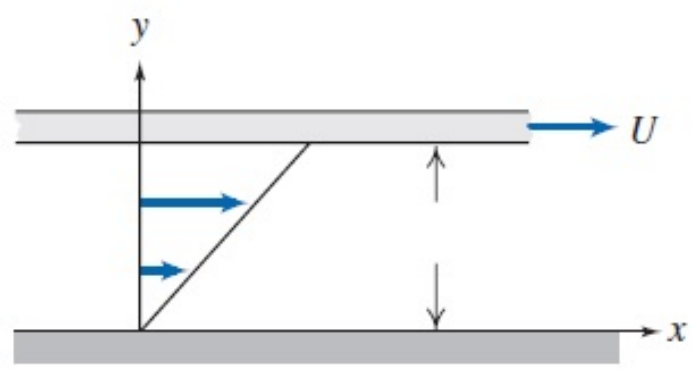

Figure 1: Simple picture.

With such setting the efforts and moments of the plate will have the following form ${ }^{*}[2]$ :

$$
\begin{aligned}
& T_{x}=C_{11} \frac{\partial u}{\partial x}+C_{12} \frac{\partial v}{\partial y}, T_{y}=C_{12} \frac{\partial u}{\partial x}+C_{22} \frac{\partial v}{\partial y}, T_{x y} \\
& =C_{66}\left(\frac{\partial u}{\partial y}+\frac{\partial v}{\partial x}\right) \\
& M_{x}=D_{11} \frac{\partial \varphi}{\partial x}+D_{12} \frac{\partial \psi}{\partial y}, M_{y}=D_{12} \frac{\partial \varphi}{\partial x}+D_{22} \frac{\partial \psi}{\partial y}, \\
& M_{x y}=D_{66}\left(\frac{\partial \varphi}{\partial y}+\frac{\partial \psi}{\partial x}\right)
\end{aligned}
$$

$$
\begin{aligned}
& N_{x}=2 n h A_{44}\left(\varphi+\frac{\partial w}{\partial x}\right), C_{44}=2 n h A_{44} ; N_{y} \\
& =2 n h A_{55}\left(\psi+\frac{\partial w}{\partial y}\right), C_{55}=2 n h A_{55}
\end{aligned}
$$

${ }^{\star}$ It is already admitted that besides $D_{16}=D_{26}=0$ we also have $C_{16}=C_{26}=0 ; C_{i j}=2 h \sum_{k=1}^{n} B_{i j}^{(k)}[3]$.

\section{Selling of the Problem}

The problem is at rectangular plate stability, when on two opposite sides equally distributed efforts act $\rho[4]$

The critical effort in this care will be determined from the following system [5]:

$$
\begin{aligned}
& D_{44}\left(\frac{\partial \varphi}{\partial x}+\frac{\partial^{2} w}{\partial x^{2}}\right)+D_{55}\left(\frac{\partial \psi}{\partial y}+\frac{\partial^{2} w}{\partial y^{2}}\right)-\rho\left(\frac{\partial^{2} w}{\partial x}\right)=0 \\
& D_{11}\left(\frac{\partial^{2} \varphi}{\partial x^{2}}\right)+D_{66}\left(\frac{\partial^{2} \varphi}{\partial y^{2}}\right)+\left(D_{12}+D_{66}\right) \frac{\partial^{2} \psi}{\partial x \partial y}=D_{44}\left(\varphi+\frac{\partial w}{\partial x}\right) \\
& \left(D_{12}+D_{66}\right) \frac{\partial^{2} \varphi}{\partial x \partial y}+D_{66}\left(\frac{\partial^{2} \varphi}{\partial x^{2}}\right)+D_{22}\left(\frac{\partial^{2} \psi}{\partial y}\right)=D_{55}\left(\psi+\frac{\partial w}{\partial y}\right)
\end{aligned}
$$

The analogous conditions of the simple joint will be [6]:

$$
\begin{aligned}
& W=\frac{\partial^{2} w}{\partial x^{2}}=\frac{\partial \varphi}{\partial x}=0 \\
& W=\frac{\partial^{2} w}{\partial y^{2}}=\frac{\partial \psi}{\partial y}=0
\end{aligned}
$$

For the sought functions satisfying these conditions we shall have [7]: 
Citation: Daryadar M (2018) The Accounting of the Transverse Slides for the Layered Composites. J Steel Struct Constr 4: 149. doi:

Page 2 of 3

$$
\begin{aligned}
& w=w_{m n} \sin \lambda_{m} x \quad \sin \mu_{n} y \\
& \varphi=\varphi_{m n} \cos \lambda_{m} x \quad \sin \mu_{n} y \\
& \psi=\psi_{m n} \sin \lambda_{m} x \quad \cos \mu_{n} y \\
& \lambda_{m}=\frac{m \pi}{a}, \mu_{n}=\frac{n \pi}{b}
\end{aligned}
$$

For definite $\mathrm{a}$ and $\mathrm{b}$ relations the critical effort will be determined by the following formula [8]:

$$
\rho \lambda_{m}^{2}=D_{44} \lambda^{2}+D_{55} \mu^{2}+\frac{\Delta 1}{\Delta}
$$

Where,

$$
\begin{aligned}
& \Delta_{1}=2 C_{44} C_{55} \lambda_{m}{ }^{2} \mu_{n}{ }^{2}+\left(D_{12}+D_{66}\right)- \\
& \left.C_{44}{ }^{2} \lambda_{m}{ }^{2}{ }^{\left(D_{22}\right.} \mu_{n}{ }^{2}+D_{66} \lambda_{m}{ }^{2}+C_{55}\right) \\
& -D_{55}{ }^{2} \mu_{n}{ }^{2}\left(D_{11} \lambda_{m}{ }^{2}+D_{66} \mu_{n}{ }^{2}+D_{44}\right) \\
& \Delta=D_{11} D_{66} \lambda_{m}{ }^{4}+D_{22} D_{66} \mu_{n}{ }^{4}- \\
& \left(D_{11} D_{22}-D_{12}{ }^{2}-2 D_{12} D_{66}\right) \lambda_{m}{ }^{2} \mu_{n}{ }^{2}+ \\
& C_{44}\left(D_{22} \mu_{n}{ }^{2}+D_{66} \lambda_{m}{ }^{2}\right)+C_{55}\left(D_{11} \lambda_{m}{ }^{2}+D_{66} \mu_{n}{ }^{2}\right)
\end{aligned}
$$

The simplest solution is obtained for one-dimensional (cylindrical bending) problem [9]:

$$
\begin{gathered}
C_{44}\left(\frac{\partial \varphi}{\partial x}+\frac{\partial^{2} w}{\partial x^{2}}\right)+P\left(\frac{\partial^{2} w}{\partial x^{2}}\right)=0 \\
D_{11} \frac{\partial^{2} \varphi}{\partial x^{2}}=C_{44}\left(\varphi+\frac{\partial w}{\partial x}\right)
\end{gathered}
$$

For the considered boundary conditions the critical effort in this care will be:

$$
P_{k p}=D_{11} \lambda_{1}^{2}\left(1-\frac{D_{11}}{C_{44}} \lambda_{1}^{2}\right)
$$

From here it can be seen that when $C_{44} \rightarrow \infty$ we obtain classical $P_{k p}=D_{11} \lambda_{1}^{2}$ result and that the transverse slide accounting brings to the minimizations of the critical effort [10]. It in the considered problem the primary state is smoothly stressed, and then now we consider a problem when the primary state is momental [11]. Patricianly, we consider the problem on testability of a layered plate, when on its external surfaces oppositely directed stresses of $\mathrm{S}$ intensively act [12]. In this care the only of font coming from the primary state will be transverse

$$
N_{1}^{0}=S . H, H=2 n h
$$

And the equations of the stability will have the form:

$$
\begin{aligned}
& C_{11}\left(\frac{\partial^{2} u}{\partial x^{2}}\right)+C_{66} \frac{\partial^{2} u}{\partial y^{2}}+\left(C_{12}+C_{66}\right) \frac{\partial^{2} v}{\partial x \partial y}+S H=0 \\
& \left(\mathcal{C}_{11}+C_{66}\right) \frac{\partial^{2} u}{\partial x \partial y}+C_{66}\left(\frac{\partial^{2} v}{\partial x^{2}}\right)+C_{22}\left(\frac{\partial^{2} v}{\partial y^{2}}\right)+S H=0 \\
& C_{44}\left(\frac{\partial \varphi}{\partial x}+\frac{\partial^{2} w}{\partial x^{2}}\right)+C_{55}\left(\frac{\partial \psi}{\partial y}+\frac{\partial^{2} w}{\partial y^{2}}\right)=0 \\
& S H \frac{\partial u}{\partial x}+C_{44}\left(\varphi+\frac{\partial w}{\partial x}\right)-D_{11}\left(\frac{\partial^{2} \varphi}{\partial x^{2}}\right)-D_{66}\left(\frac{\partial^{2} \varphi}{\partial y^{2}}\right)- \\
& \left(D_{12}+D_{66}\right) \frac{\partial^{2} \varphi}{\partial x \partial y}=0 \\
& S H \frac{\partial v}{\partial x}+C_{55}\left(\psi+\frac{\partial w}{\partial y}\right)-\left(D_{12}+D_{66}\right) \frac{\partial^{2} \varphi}{\partial x \partial y}- \\
& D_{66}\left(\frac{\partial^{2} \psi}{\partial x^{2}}\right)-D_{22}\left(\frac{\partial^{2} \psi}{\partial y^{2}}\right)=0
\end{aligned}
$$

For the freely supported plate:

$$
\begin{aligned}
& u=u_{m n} \sin \lambda_{m} x \quad \sin \mu_{n} y \\
& v=v_{m n} \cos \lambda_{m} x \quad \sin \mu_{n} y \\
& w=w_{m n} \sin \lambda_{m} x \quad \cos \mu_{n} y \\
& \varphi=\varphi_{m n} \cos \lambda_{m} x \quad \sin \mu_{n} y \\
& \psi=\psi_{m n} \sin \lambda_{m}^{x} \quad \cos _{n} y
\end{aligned}
$$
13]:

$$
\operatorname{det}\left\|a_{i j}\right\|=0
$$

Where

$$
\begin{aligned}
& a_{11}=-C_{11} \lambda^{2}-C_{66} \mu^{2}, a_{12}=a_{21}=\left(C_{12}+C_{66}\right) \lambda^{2} \mu^{2} \\
& a_{41}=a_{14}=-S H=-a_{25}=-a_{52}, a_{22}=-C_{22} \mu^{2}-C_{66} \lambda^{2} \\
& a_{33}=-C_{55} \mu^{2}-C_{44} \lambda^{2}, a_{43}=a_{34}=-C_{44} \lambda \\
& a_{35}=a_{55}=-C_{55} \mu, a_{44}=-\left(C_{44}+D_{11} \lambda^{2}+D_{66} \mu^{2}\right) \\
& a_{45}=a_{54}=\left(D_{12}+D_{66}\right) \lambda \mu, a_{55}=-\left(C_{55}+D_{66} \lambda^{2}-D_{22} \mu^{2}\right)
\end{aligned}
$$

\section{Conclusion}

The rest of coefficient are equal to zero and in the last expressions for shortness on and magnitudes index has not been set.

As in the previous problem let's consider the care of the cylinder bending: 
Citation: Daryadar M (2018) The Accounting of the Transverse Slides for the Layered Composites. J Steel Struct Constr 4: 149. doi:

Page 3 of 3

$$
\begin{aligned}
& C_{11} \frac{\partial^{2} u}{\partial x^{2}}+S H \frac{\partial \varphi}{\partial x}=0 \\
& C_{44}\left(\frac{\partial^{2} w}{\partial x^{2}}+\frac{\partial \varphi}{\partial x}\right)=0 \\
& S H \frac{\partial u}{\partial x}+C_{44}\left(\frac{\partial w}{\partial x}+\varphi\right)-D_{11}\left(\frac{\partial^{2} \varphi}{\partial x^{2}}\right)=0
\end{aligned}
$$

The critical effort will be determined by the following formula:

$$
S h= \pm \sqrt{C_{11} D_{11} \lambda_{1}}
$$

In fact in one-dimensional problem the transverse sliders accounting does not change the value of the classic one.

\section{Suggested Technology has some Advantages}

- It has a optimization system;

- It is cheaper;

- Getting a high qualitative production;

\section{Acknowledgments}

I would like to express sincere thanks to my research supervisor, Professor LA Movsisyan, whose helps, stimulating suggestions, and encouragement helped me at all times in doing the research. Finally, I would like to thank my parents, sister, and all people, that, unwavering support enabled me to complete this work.

\section{References}

1. Fleming JF, Herrmann G, Mooney I (1965) Buckling of Structural Elements Subject to Surface Shear. J Applied Mechanics 32: 194-195.
2. Movsisyan LA, Peshtmaliyan DV (1973) On the stability equations and plates vibrations Izvestiya AN Arm. SSR. Mechanics 26: 18-28.

3. Aghalovyan L (2009) Asymptotical theory of anisotropic plates and shells. M. Nauka: 414.

4. Movsisyan LA, Peshtmaliyan DV. On the stability equations and plates vibrations Izvestiya AN Arm. SSR. Mechanics.

5. Ambartsumyan SA, Belubekyan MV (1994) On bending waves localized along the edge of a plate. International Applied Mechanics 30: 135-140.

6. Belubekyan VM (2004) On the problem of stability of plate under account of transverse shears. In Proc Rus Sc Academy, MTT conference 2: 126-131.

7. Bank LC, Yin J (1994) Buckling of Orthotropic Plates with Free and Rotationally Restrained Unloaded Edges. Thin-Walled Structures 24: 83-96.

8. Lekhnitskii SG (1968) Anisotropic Plates. Gorden and Breach, New York, p: 534 .

9. Mkrtchyan HP (2003) Localized bending waves in an elastic orthotropic plate. Proceedings of National Academy of Sciences of Armenia. Mechanics 56: 66-68.

10. Movsisyan LA (2008) On the stability of rectangular plate with two free edges. Proceedings of Armenian National Science Academy, Mechanics 61: 33-35.

11. Movsisyan LA (2011) The stability of cylindrical ring under punches. Proceedings of NAS RA: Mechanics 64: 32-39.

12. Piliposyan GT, Belubekyan MV, Ghazaryan KB (2010) Localized bending waves in a transversely isotropic plate. J Soun Vib 329: 3596-3605.

13. Piliposian GT, Ghazaryan KB (2011) Localized bending vibrations of piezoelectric plates. Waves in random and complex media 21: 418-433. 